\title{
Pituitary adenomas in the setting of multiple endocrine neoplasia type 1: a single-institution experience
}

\author{
Salomon Cohen-Cohen, MD, ${ }^{1}$ Desmond A. Brown, MD, PhD, ${ }^{1}$ Benjamin T. Himes, MD, ${ }^{1}$ \\ Lydia P. Wheeler, MD, ${ }^{1}$ Michael W. Ruff, MD, ${ }^{2}$ Brittny T. Major, MS, ${ }^{3}$ Naykky M. Singh Ospina, MD, ${ }^{4}$ \\ John L. D. Atkinson, MD, ${ }^{1}$ Fredric B. Meyer, MD, ${ }^{1}$ Irina Bancos, MD, ${ }^{4}$ William F. Young Jr., MD, ${ }^{4}$ and \\ Jamie J. Van Gompel, MD ${ }^{1,5}$
}

Departments of ${ }^{1}$ Neurological Surgery, ${ }^{2}$ Neurology, ${ }^{3}$ Biostatistics, ${ }^{4}$ Endocrinology, and ${ }^{5}$ Otolaryngology-Head and Neck Surgery, Mayo Clinic, Rochester, Minnesota

\begin{abstract}
OBJECTIVE Multiple endocrine neoplasia type 1 (MEN1) is a rare, autosomal-dominant tumor disorder characterized by the development of pituitary tumors and other endocrine neoplasms. Diagnosis is made clinically based on the development of 2 or more canonical lesions (parathyroid gland, anterior pituitary, and enteropancreatic tumors) or in family members of a patient with a clinical diagnosis of MEN1 and the occurrence of one of the MEN1-associated tumors. The goal of this study was to characterize pituitary tumors arising in the setting of MEN1 at a single institution. The probability of tumor progression and the likelihood of surgical intervention in patients with asymptomatic nonfunctional pituitary adenomas were also analyzed.
\end{abstract}

METHODS A retrospective review of a prospectively maintained institutional database was performed for patients with MEN1 diagnosed from 1970 to 2017. Data included patient demographics, tumor characteristics, treatment strategies, and outcomes.

RESULTS A review of the database identified 268 patients diagnosed with MEN1, of whom 158 (59\%) were female. Among the 268 patients, 139 (51.8\%) had pituitary adenomas. There was a higher prevalence in women than in men $(65 \%$ vs $35 \%$, p < 0.005). Functional adenomas $(57 \%)$ were more common. Prolactin-secreting adenomas were the most common functional tumors. Macroadenomas were seen in $27 \%$ of patients and were more likely to be symptomatic and locally aggressive $(p<0.001)$. Forty-nine patients $(35 \%)$ underwent transsphenoidal resection at some point during their disease course. In 52 patients who were initially observed with MEN1 asymptomatic nonfunctional adenomas, only 5 $(10 \%)$ progressed to need surgery. In MEN1 patients, an initial parathyroid lesion is most likely followed in order by pituitary, pancreatic, adrenal, and, finally, rare carcinoid tumors.

CONCLUSIONS Asymptomatic nonfunctional pituitary adenomas in patients with MEN1 may be followed safely with MRI. In this series, parathyroid tumors developed at the lowest median age of all cardinal tumors, and development of additional cardinal MEN1 lesions followed a predictable pattern. This pattern of disease progression could have significant implications for disease surveillance in clinical practice and may help to target clinical resources to the lesions most likely to develop next. This may aid with early detection and treatment and warrants further study.

https://thejns.org/doi/abs/10.3171/2020.1.JNS193538

KEYWORDS MEN1; pituitary adenomas; asymptomatic; transsphenoidal surgery; pituitary surgery

$\mathrm{M}$ ULTIPLE endocrine neoplasia type 1 (MEN1) is an autosomal-dominant disorder attributed to a germline pathogenic variant of the tumor suppressor menin gene located at 11q13. ${ }^{1}$ Clinically, the disorder includes primary hyperparathyroidism; neuroendocrine tumors of the pancreas, duodenum, thymus, and bronchi; adrenal tumors; and pituitary tumors. ${ }^{2}$ While the greatest mortality in MEN1 is attributed to metastatic pancreatic and thoracic neuroendocrine tumors, ${ }^{3}$ pituitary involvement remains a significant cause of morbidity. ${ }^{4,5}$ Consequently, several reports have been published that have aimed to categorize the incidence, clinical features, pathology, and treatment of pituitary disease in MEN1 patients. $^{4-12}$

ABBREVIATIONS ACTH = adrenocorticotropic hormone; GH = growth hormone; IGF-1 = insulin-like growth factor-1; MEN1 = multiple endocrine neoplasia type 1; PH = plurihormone; $\mathrm{PRL}=$ prolactin.

SUBMITTED December 31, 2019. ACCEPTED January 27, 2020.

INCLUDE WHEN CITING Published online April 3, 2020; DOI: 10.3171/2020.1.JNS193538. 
Among functional pituitary tumors in the general population, prolactinomas are the modal type, accounting for approximately $40 \%$ of such neoplasms. ${ }^{13}$ In MEN1-related pituitary adenomas, it remains unclear whether there are significant differences in the secretory hormone patterns. A number of studies have shown a preponderance of prolactin (PRL)-producing tumors in the setting of MEN1.5,6,9,11

The clinical success of dopamine agonist therapy in the treatment of prolactinomas, combined with the low probability of surgical cure in cases of macroprolactinomas, has limited the indications for surgical intervention in these cases. In presumed sporadic tumors, surgery for prolactinomas is limited to patients with persistent hyperprolactinemia or worsening mass effect in the setting of maximal medical therapy, or those in whom there are intolerable adverse effects to dopamine agonists., ${ }^{9,14,15}$ Thus, there are likely fundamental differences in the pathophysiology of tumors requiring surgery in comparison with those that do not, and such nuances likely extend to tumors arising in the setting of MEN1. This question has not been specifically addressed in the literature by limiting analysis to patients with MEN1 who required pituitary tumor resection.

Despite previous studies of pituitary disease in MEN1, few have assessed the outcomes of patients with asymptomatic pituitary adenomas, and none have analyzed the probability of tumor progression and the likelihood of surgical intervention.

Another controversial aspect of care for patients with MEN1 syndrome is defining the appropriate level and nature of surveillance. While the nature of the disease process is to have lesions develop in multiple organ systems over time, the timing of this progression is not well described.

The objective of this study was to characterize pituitary tumors arising in the setting of MEN1 at a single institution, including patients with asymptomatic adenomas, and describe their outcomes. We also report a novel finding in the timing and progression of lesions in MEN1 patients that may help with disease surveillance.

\section{Methods}

This study was approved by our institutional review board. A prospectively collected internal database linked to our institution's electronic medical record was used to identify patients with a clinical diagnosis of MEN1 treated at our institution between 1970 and 2017. Patients were considered to have MEN1 if they had tumors arising from at least 2 of the 3 main MEN1-associated tissues (pituitary, parathyroid, or pancreas); if they had any single cardinal tumor and a first-degree relative affected by the syndrome; or if they had a germline inactivating MEN1 gene pathogenic variant, in accordance with accepted guidelines. ${ }^{16}$ Patient demographics, tumor characteristics, treatment strategies, and outcomes were recorded.

\section{Endocrinology, Ophthalmology, and Radiology Evaluations}

All patients underwent a baseline preoperative hormone evaluation, and the workup for functional adenomas was performed in collaboration with the endocrinology and neuro-ophthalmology teams. In patients with nonfunctioning pituitary microadenomas $(<1 \mathrm{~cm})$, follow-up MRI was performed every $2-3$ years, and PRL and insulin-like growth factor-1 (IGF-1) levels were obtained annually. For patients with nonfunctioning macroadenomas $(>1 \mathrm{~cm})$ or those who underwent a transsphenoidal resection, the follow-up consisted of annual MRI and PRL, IGF-1, free T4, cortisol, and gonadal steroid measurements. Followup visual fields are only done if the adenoma contacted the optic apparatus. Tumor progression was defined when there was a significant growth on follow-up MRI.

Patients with newly diagnosed MEN1 undergo followup with annual blood tests for calcium, pancreatic neuroendocrine tumor markers (gastrin, glucagon, pancreatic polypeptide, and chromogranin A), and pituitary tumor markers (PRL and IGF-1), pituitary-directed head MRI every 2-3 years, imaging of the pancreas with either pancreas CT or endoscopic ultrasound every 1-2 years (every year when younger and every 2 years when older), and chest CT every 5 years.

\section{Remission Criteria}

In secreting adenomas, remission was determined using modern criteria: in patients with growth hormone (GH)-secreting tumors, IGF-1 level in the age-adjusted normal range and a $\mathrm{GH}$ level less than $1.0 \mu \mathrm{g} / \mathrm{L}$ from a random $\mathrm{GH}$ measurement ${ }^{17}$ and in patients with Cushing's disease, morning serum cortisol $\leq 5 \mu \mathrm{g} / \mathrm{dl}$ or urinary free cortisol $<10-20 \mu \mathrm{g} / \mathrm{dl}$ within 7 days of selective tumor resection. ${ }^{18}$ Urinary free cortisol levels and/or salivary cortisol were evaluated subsequently every 3-6 months postoperatively for 2 years and annually thereafter to rule out recurrence. Patients with PRL-secreting tumors were considered in remission if their plasma PRL level returned to normal without visible radiological tumor remnants and without requiring dopamine agonist therapy.

The indications for surgical intervention in patients with prolactinomas included medication intolerance, resistant tumors, and patient preference.

\section{Statistical Analysis}

Continuous data are presented as the median with range and categorical variables as percentages. The KruskalWallis test was used to analyze continuous variables, and the chi-square test was used for categorical variables. The period of tumor occurrence was defined as the time from date of birth to the date of tumor diagnosis. The median delay between initial and subsequent tumors was defined as the time from diagnosis of the first tumor to the diagnosis of a subsequent lesion. Kaplan-Meier analysis was used to estimate the rate of developing outcomes (i.e., time to first tumor, time to pituitary tumor, median delay). Sex differences in the time to tumor occurrence were tested using the log-rank test. Cox proportional hazard models were used to assess the association of risk factors on the time to tumor diagnosis. Logistic regression was used to determine independent risk factors for positive MEN1 gene testing. For all analyses, $\mathrm{p}<0.05$ was considered statistically significant. All analyses were performed using SAS version 9.3 (SAS Institute). 
TABLE 1. Diagnostic criteria in 268 patients with MEN1

\begin{tabular}{|c|c|c|c|c|c|c|}
\hline & $\begin{array}{c}\text { Menin } \\
\text { Mutation }\end{array}$ & $\begin{array}{l}\text { Family } \\
\text { History }\end{array}$ & $\begin{array}{l}\text { Pituitary } \\
\text { Tumor }\end{array}$ & $\begin{array}{l}\text { Parathyroid } \\
\text { Tumor }\end{array}$ & $\begin{array}{c}\text { Enteropancreatic } \\
\text { Tumor }\end{array}$ & $\begin{array}{l}\text { No. of Pts } \\
(\%)\end{array}$ \\
\hline \multirow{8}{*}{$\begin{array}{l}\text { Pts w/ family Hx } \\
\text { MEN1 \& occurrence } \\
\text { of MEN1-assoc } \\
\text { tumors }\end{array}$} & - & + & + & - & - & $1(0.4)$ \\
\hline & - & + & - & + & - & $16(6)$ \\
\hline & - & + & - & - & + & $4(1.4)$ \\
\hline & - & + & + & + & - & $5(1.9)$ \\
\hline & - & + & - & + & + & 35 (13.1) \\
\hline & - & + & + & - & + & $3(1.1)$ \\
\hline & - & + & + & + & + & $39(14.5)$ \\
\hline & Total & & & & & $103(38.4)$ \\
\hline \multirow{5}{*}{$\begin{array}{l}\text { Pts w/ } \geq 2 \text { primary } \\
\text { MEN1-assoc tumors } \\
\text { w/o family Hx MEN1 }\end{array}$} & - & - & + & + & - & 17 (6.3) \\
\hline & - & - & - & + & + & $29(10.8)$ \\
\hline & - & - & + & - & + & $4(1.5)$ \\
\hline & - & - & + & + & + & $25(9.3)$ \\
\hline & Total & & & & & $75(28)$ \\
\hline \multirow{9}{*}{$\begin{array}{l}\text { No. of pts w/ menin } \\
\text { gene mutation }\end{array}$} & + & $+1-$ & + & - & - & $6(2.2)$ \\
\hline & + & $+1-$ & - & + & - & $9(3.6)$ \\
\hline & + & $+1-$ & - & - & + & $4(1.4)$ \\
\hline & + & $+1-$ & + & + & - & $9(3.4)$ \\
\hline & + & $+1-$ & - & + & + & $27(10)$ \\
\hline & + & $+1-$ & + & - & + & $3(1.1)$ \\
\hline & + & $+1-$ & + & + & + & $27(10)$ \\
\hline & + & $+1-$ & - & - & - & $5(1.9)$ \\
\hline & Total & & & & & $90(33.6)$ \\
\hline
\end{tabular}

Assoc $=$ associated; $\mathrm{Hx}=$ history of; pts $=$ patients; $+=$ positive $;-=$ negative $;+/-=$ there $\mathrm{might} / \mathrm{might}$ not be a family history.

\section{Results}

\section{Patient Demographics}

Two hundred sixty-eight patients with MEN1 were included. There were $158(59 \%)$ females and $110(41 \%)$ males. Genetic testing for MEN1 germline mutation was performed in 101 patients $(37.7 \%)$, and it was positive in 90 patients $(89.1 \%)$. The remaining patients met clinical diagnostic criteria of MEN1 as follows: 103 (38.4\%) patients had a positive family history along with at least 1 canonical neoplasm; 75 (28\%) patients had no known family history but had at least 2 MEN1-associated neoplasms. Table 1 summarizes the diagnostic criteria met for the patients in the study.

Among this cohort of MEN1 patients, we encountered 139 patients $(52 \%)$ with pituitary adenomas. There was a higher prevalence in women than in men $(65 \%$ vs $35 \%$, p $<0.005$ ). The mean age at onset of pituitary adenoma was 36 years with a range between 5 and 80 years. In addition to pituitary adenomas, patients were also diagnosed with parathyroid adenomas in 221 cases (82\%), enteropancreatic tumors in 200 cases (74\%), adrenal tumors in 52 cases (19\%), and carcinoid tumors in 30 cases (11\%). The pituitary tumor was the sole neoplasm in only 7 (5\%) cases. These data are summarized in Table 2.

\section{Pituitary Adenoma Characteristics}

Among the 139 pituitary adenomas, 79 (57\%) were functional and 60 (43\%) were nonfunctional. There were 38 macroadenomas $(27 \%)$ and 101 microadenomas (73\%). The median macroadenoma size at maximum diameter was $17 \mathrm{~mm}$ (range $10-80 \mathrm{~mm}$ ). Macroadenomas were more likely to be symptomatic and locally aggressive, accounting for all patients with visual deficit (13 patients), all tumors with suprasellar extension (14 patients), and 15 of 16 (94\%) tumors showing cavernous sinus invasion (Knosp grade III or IV) $(\mathrm{p}<0.001)$. PRL-secreting adenomas were the most common functional tumors $(\mathrm{n}=$ $60,76 \%$ ), followed by plurihormone (PH)-secreting adenomas (all secreted PRL and another hormone; $\mathrm{n}=9$, $11 \%)$, $\mathrm{GH}$-secreting adenomas $(\mathrm{n}=6,8 \%)$, and adrenocorticotropic hormone (ACTH)-secreting adenomas $(\mathrm{n}=4$, $5 \%$ ). PH-secreting tumors were large and locally aggressive, with 7 macroadenomas (78\%), 3 (33\%) with suprasellar extension, $3(33 \%)$ with cavernous sinus invasion, and $2(22 \%)$ resulting in visual defects. PH-secreting tumors were more likely to be a macroadenoma than were tumors producing a single hormone $(\mathrm{p}=0.047)$. These results are summarized in Table 3.

\section{Treatment Strategies, Outcomes, and Follow-Up}

Forty-nine patients $(35 \%)$ underwent transsphenoidal resection, and 90 patients $(65 \%)$ were observed or treated with dopamine agonist therapy. Of the 49 patients, 13 (27\%) had nonfunctional and 36 (73\%) had functional ad- 
TABLE 2. Distribution of the main endocrine lesions among the 268 patients

\begin{tabular}{|c|c|c|c|}
\hline Feature & Female & Male & Total \\
\hline Total MEN1 pts in cohort & 158 & 110 & 268 \\
\hline Family Hx MEN1 & 86 & 77 & 163 \\
\hline Menin gene mutation present & 52 & 38 & 90 \\
\hline $\begin{array}{l}\text { Median age at MEN1 diagnosis, } \\
\text { yrs (range) }\end{array}$ & 38 & 32.5 & $36(3-83)$ \\
\hline Diagnosed pituitary tumor & 90 & 49 & 139 \\
\hline $\begin{array}{l}\text { Median age at pituitary tumor } \\
\text { diagnosis, yrs (range) }\end{array}$ & 35.5 & 36 & $36(5-80)$ \\
\hline Pituitary surgery performed & 36 & 13 & 49 \\
\hline $\begin{array}{l}\text { Median age at pituitary surgery, } \\
\text { yrs (range) }\end{array}$ & 36 & 32.5 & $37(14-75)$ \\
\hline Diagnosed parathyroid tumor & 141 & 97 & 238 \\
\hline $\begin{array}{l}\text { Median age at parathyroid tumor } \\
\text { diagnosis, yrs (range) }\end{array}$ & 38 & 32 & $36(6-83)$ \\
\hline Parathyroidectomy & 131 & 90 & 221 \\
\hline $\begin{array}{l}\text { Median age at parathyroidectomy, } \\
\text { yrs (range) }\end{array}$ & 35 & 32 & $33(7-80)$ \\
\hline Pancreatic tumor diagnosis & 121 & 79 & 200 \\
\hline $\begin{array}{l}\text { Median age at pancreatic tumor } \\
\text { diagnosis, yrs (range) }\end{array}$ & 40 & 30 & $40(7-83)$ \\
\hline Pancreatectomy & 64 & 54 & 118 \\
\hline $\begin{array}{l}\text { Median age at pancreatectomy, } \\
\text { yrs (range) }\end{array}$ & 40.0 & 41 & $40(7-74)$ \\
\hline Adrenal tumor diagnosis & 30 & 22 & 52 \\
\hline $\begin{array}{l}\text { Median age at adrenal tumor } \\
\text { diagnosis, yrs (range) }\end{array}$ & 45.5 & 43.5 & $44.5(17-77)$ \\
\hline Adrenalectomy & 6 & 4 & 10 \\
\hline $\begin{array}{l}\text { Median age at adrenalectomy, yrs } \\
\text { (range) }\end{array}$ & 51.5 & 49 & $50(31-63)$ \\
\hline Carcinoid diagnosis & 15 & 15 & 30 \\
\hline $\begin{array}{l}\text { Median age at carcinoid diagnosis, } \\
\text { yrs (range) }\end{array}$ & 44 & 41 & $42(21-68)$ \\
\hline Carcinoid resection & 4 & 7 & 11 \\
\hline $\begin{array}{l}\text { Median age at carcinoid resection, } \\
\text { yrs (range) }\end{array}$ & 57 & 48 & $52(33-63)$ \\
\hline
\end{tabular}

Values represent the number of patients unless stated otherwise.

enomas. Of these 49 patients, surgery was the first line of treatment in 41 patients (84\%). Eight patients $(20 \%)$ had nonfunctional adenomas, and 33 patients (80\%) had functional adenomas: 21 (64\%) PRL-secreting, 5 (15\%) $\mathrm{PH}$-secreting, 4 (12\%) GH-secreting, and 3 (9\%) ACTHsecreting adenomas. The indication for surgery in these 41 patients was the presence of visual symptoms or cavernous sinus invasion in 24 patients $(59 \%)$ and patient preference in $17(41 \%)$. The tumors in 3 patients $(6 \%)$ with functional adenomas failed dopamine agonist therapy and required a subsequent surgery. Of the 36 patients with functional adenomas who underwent a transsphenoidal resection, $29(81 \%)$ achieved remission. Of the patients who did not achieve remission ( $\mathrm{n}=7,19 \%), 3$ (43\%) had a PH-secreting, 3 (43\%) had a PRL-secreting, and $1(14 \%)$ had a GH-secreting adenoma. The median follow-up period in the group of patients with functional tumors who underwent a transsphenoidal resection was 18 years (range $1-41$ years).

In 52 patients who were initially observed with asymptomatic nonfunctional pituitary adenomas with 298 patient-years of follow-up, only $5(10 \%)$ progressed to need surgery. The main reason for surgery was tumor growth and proximity to the chiasm, but none of these patients had visual deficits or pituitary dysfunction. The median time between diagnosis and surgery for these 5 patients was 99 months (range 2-291 months). The Kaplan-Meier plot of these patients is shown in Fig. 1. Three patients with nonfunctional adenomas underwent surgery as their first line of treatment secondary to visual impairment. The median follow-up period for the surgical patients with nonfunctional adenomas was 9 years (range 1-37 years).

Tumor recurred in 10 patients ( 9 in the surgical group and 1 in the nonsurgical group), which prompted treatment with fractionated radiotherapy (20\%). The latter patient had a giant PH-secreting tumor and elected for dopamine agonist therapy. The tumor progressed despite treatment, and the patient underwent radiotherapy. The remaining patients who were observed or treated with dopamine agonist therapy did not need other types of adjuvant therapy. The median follow-up period for the nonsurgical patients was 7 years (range 1-30 years). During this follow-up period, 28 patients (20\%) died (16 in the surgical group and 12 in the nonsurgical group). None of the deaths were related to pituitary adenomas. Twelve patients (9\%), all in the nonsurgical group, were lost to follow-up.

\section{Timing of MEN1 Features}

The median age at diagnosis of the first cardinal MEN1 tumor was 32.5 years (range 3-83 years) and 38 years (range 6-74 years) for males and females, respectively $(\mathrm{p}=0.17)$. Hypercalcemia may have emerged earlier but without a proper diagnosis of MEN1. Kaplan-Meier and Cox analyses were used to determine the median delay between an initial and subsequent cardinal tumor (Table 4). Parathyroid tumors typically present initially and are subsequently followed by pituitary, pancreatic, adrenal, carcinoid, and then adrenal tumors $(\mathrm{p}=0.0037)$. Consistent with this, the median time to a second MEN1 tumor if the initial tumor was a parathyroid tumor was 14.6 years versus 11 years (range 3-22 years) following an initial pancreatic lesion, 2.5 years following an initial adrenal tumor, 2.0 years following a pituitary tumor, and only 5 months following a carcinoid tumor $(\mathrm{p}=0.0007)$.

\section{Discussion}

A prior case series from our institution of 52 patients with MEN1 who underwent resection of pituitary neoplasms revealed a propensity toward PRL- and GH-producing tumors without significant differences in tumor size, invasiveness, or demographic factors such as age or sex. ${ }^{10}$ In a subsequent large multicenter retrospective study of 324 patients with MEN1 including 136 patients (42\%) with pituitary disease, $62 \%$ secreted PRL, 9\% secreted $\mathrm{GH}, 4 \%$ secreted ACTH, and $10 \%$ were multihormonal. ${ }^{5}$ 
TABLE 3. Summary of clinical and demographic characteristics of 139 patients with MEN1 and pituitary adenomas

\begin{tabular}{lcccccccc}
\hline & \multirow{2}{*}{ No. of Pts } & \multicolumn{2}{c}{ Sex } & & \multicolumn{2}{c}{ Size } & & \\
Type & $(\%)$ & Male & Female & Age, Yrs* & Macro & Micro & VS & CSI \\
\hline NF & $60(43.2)$ & $22(36.7)$ & $38(63.3)$ & $41(5-80)$ & $10(16.7)$ & $50(83.3)$ & $3(1.7)$ & $5(8.3)$ \\
\hline $\mathrm{PRL}$ & $60(43.2)$ & $19(31.7)$ & $41(68.3)$ & $30(14-73)$ & $18(30)$ & $42(70)$ & $6(10)$ & $6(10)$ \\
\hline $\mathrm{PH}$ & $9(6.5)$ & $6(66.7)$ & $3(33.3)$ & $38(15-62)$ & $7(77.8)$ & $2(22.2)$ & $2(22.2)$ & $3(33.3)$ \\
\hline $\mathrm{GH}$ & $6(4.3)$ & $2(33.3)$ & $4(66.7)$ & $47(37-69)$ & $2(33.3)$ & $4(66.7)$ & $1(16.7)$ & $1(16.7)$ \\
\hline $\mathrm{ACTH}$ & $4(2.9)$ & 0 & $4(100)$ & $32(20-55)$ & $1(25)$ & $3(75)$ & $1(25)$ & $1(25)$ \\
\hline
\end{tabular}

CSI = cavernous sinus invasion (Knosp III or IV); macro = macroadenoma; micro = microadenoma; NF = nonfunctional; VS = visual symptoms.

* Median age at diagnosis (range).

These percentages are consistent with the data found in our study for patients with MEN1 in whom surgery was performed. Prolactinomas were less likely than other tumor types to be macroadenomas and were diagnosed at younger ages. This finding was again consistent with previously published reports and likely reflects the earlier clinical attention attained by prolactinomas due to symptomatic amenorrhea and galactorrhea.

The prevalence of macroadenomas in our MEN1 cohort (27\%) was lower than that in Vergès and colleagues' previous report $(85 \%) .{ }^{5}$ However, macroadenomas tended to be more aggressive in suprasellar extension, invasiveness, and compromise of vision and thus more often managed surgically. Interestingly, functional PH tumors were more likely to become macroadenomas. It is unclear whether this finding represents an underlying increase in the proliferative index of $\mathrm{PH}$ tumors such that the lag time between initiation and presentation is reduced, lower blood levels of individual hormones such that there is increased time to clinical detection, and/or delayed diagnosis secondary to a more nuanced clinical picture in the setting of multiple hormonal dysregulation syndromes. Furthermore, given that Vergès et al.'s series was published in

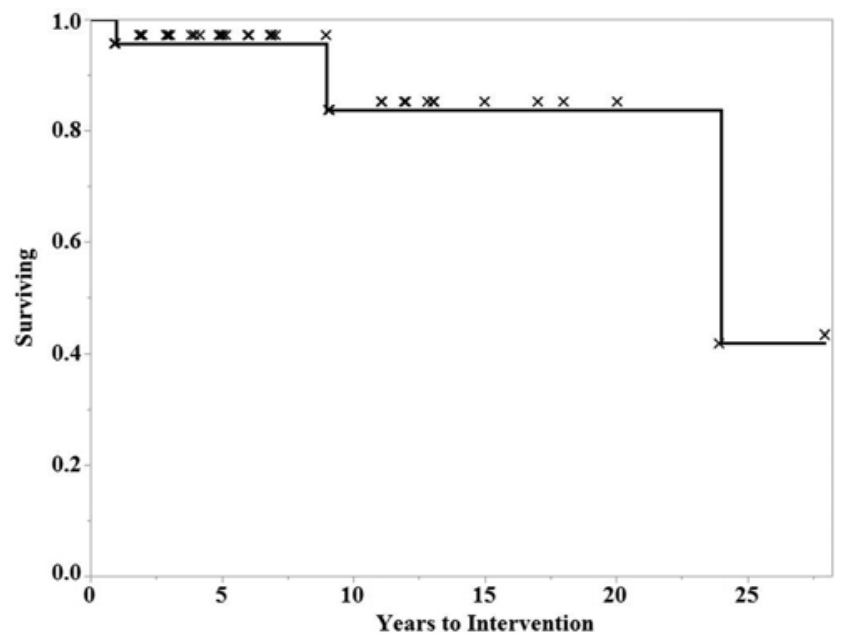

FIG. 1. Kaplan-Meier plot of the time from detection to surgery in patients with incidentally found nonfunctional adenomas.
1991, it is also likely that MRI resolution has improved in the intervening time, making it easier to identify smaller tumors. Therefore, a shift from $85 \%$ macroadenomas to $27 \%$ in this study could be explained by a detection bias.

The prevalence of pituitary disease in our series was $52 \%$, higher than frequencies reported by Marx et al. $(47 \%),{ }^{19} \mathrm{O}^{\prime}$ Brien et al. (43\%), ${ }^{10}$ Vergès et al. (42\%), ${ }^{5}$ de Laat et al. (38\%), ${ }^{8}$ Giusti et al. (37\%), ${ }^{20} \mathrm{Wu}$ et al. (32\%), ${ }^{12}$ Burgess et al. (18\%), ${ }^{4}$ and Trump et al. (29.5\%). ${ }^{21}$ However, this rate was lower than that reported by Ito et al. (58\%). ${ }^{3}$ Pituitary disease was the first manifestation of MEN1 in $22 \%$ of cases, similar to rates in previous reports., ${ }^{9,22}$ The incidence of concurrent primary hyperparathyroidism (82\%) and enteropancreatic (74\%) neuroendocrine tumors was also similar to previous literature ${ }^{5,8,12}$ However, again, given the ability to detect smaller tumors within the pituitary gland with higher-resolution MRI, this may impact these numbers and demonstrate a shift toward earlier detection of concomitant disease and improved surveillance.

TABLE 4. Timing of tumors

\begin{tabular}{lcc}
\hline & $\begin{array}{c}\text { Median Age } \\
\text { (yrs) at } \\
\text { Occurrence } \\
\text { of 1st Tumor }\end{array}$ & $\begin{array}{c}\text { p Value } \\
\text { (log rank) }\end{array}$ \\
\hline Time to any 1st tumor by sex & 38 & \\
\hline Female & 32.17 & \\
\hline Male & & 0.0037 \\
\hline Time to 1st tumor by type & 31.5 & \\
\hline Parathyroid & 35.6 & \\
\hline Pituitary & 41.5 & \\
\hline Pancreatic & 49.3 & \\
\hline Adrenal & 51.4 & \\
\hline Carcinoid & & 0.0007 \\
\hline Time to 2nd tumor given 1st tumor type & 14.6 & \\
\hline Parathyroid & 2.0 & \\
\hline Pituitary & 11.4 \\
\hline Pancreatic & 2.5 \\
\hline Adrenal & 0.39 \\
\hline Carcinoid &
\end{tabular}


Presenting symptoms of MEN1 were comparable with those in previous literature, with the greatest presentations related to symptoms of hyperparathyroidism.

The increased female-to-male ratio in MEN1 patients with pituitary adenoma is similar to what has been observed in prior studies of both MEN1 and non-MEN1 patients. ${ }^{5,8,10,13,23}$ As MEN1 occurs in the setting of a somatic pathogenic variant, it is likely that behavioral patterns are responsible for the increased representation in female patients. While estrogens are implicated in pituitary hyperplasia, lactotroph replication, and pathogenesis of pituitary adenomas, ${ }^{14}$ prolactinomas were found at similar rates in males and females.

It is important to understand the natural history of asymptomatic nonfunctional adenomas for their treatment management and follow-up. ${ }^{24-26}$ In this study, we found that of 52 patients with a total of 298 patient-years of followup, only 5 had tumor progression. Therefore, observation appears to be a very safe strategy. Furthermore, this may suggest the natural history of any pituitary tumor, with or without MEN1, that presents asymptomatically can be observed safely in most patients.

Defining the appropriate level of care and nature of surveillance in patients with MEN1 has been a controversial topic. Current practice guidelines for the management of patients with MEN1 suggest that presymptomatic lesion treatment may benefit patient outcomes. ${ }^{16}$ In our series, parathyroid tumors developed at the lowest median age of all cardinal tumors, and development of additional cardinal MEN1 lesions followed a predictable pattern. An initial parathyroid lesion is most likely followed in order by a pituitary, pancreatic, adrenal, and, finally, rare carcinoid tumors. A characteristic pattern of disease progression given a specific type of initial tumor could have significant implications for disease surveillance in clinical practice and may help to target clinical resources to the lesions most likely to develop next. This may aid with early detection and treatment. Representing a shift in management of pituitary tumors, a fair number of tumors in this series are now under surveillance, and we plan on reporting our experience with this in a subsequent paper.

Testing a patient for MEN1 with a germline mutation is reserved for patients with 2 or more primary MEN1 tumor types, all first-degree relatives of known MEN1 mutation carriers, and individuals with suspicious or atypical MEN1 (e.g., multiple parathyroid tumors, gastrinoma, or multiple pancreatic neuroendocrine tumors). ${ }^{16}$ We believe that all patients with newly diagnosed pituitary tumors should be screened for MEN1, but not with germline mutation testing. Instead, serum calcium should be measured due to the high penetrance of primary hyperparathyroidism in MEN1. If the serum calcium is normal, the risk of having MEN1 is very low.

\section{Limitations}

We acknowledge the limitations of this study, which include those inherent to an observational retrospective, single-center study. However, given the rarity of this disease, this large, single-institution cohort can provide valuable guidance to clinicians. Another limitation to this study is the absence of a control group of patients with pi- tuitary adenomas without MEN1 to compare the primary outcomes.

\section{Conclusions}

Pituitary tumors occurring in the setting of MEN1 share many of the clinical features of sporadic pituitary tumors. Observation with serial MRI in patients with nonfunctional asymptomatic pituitary adenomas with MEN1 appears to be a safe management strategy. An ordered progression of lesion development may potentially allow the clinician to manage active lesions while proactively devoting clinical attention to lesions most likely to become clinically apparent in the near term. Such a strategy may help to reduce the anxiety of surveillance for both patients and practitioners and increase treatment efficiency.

\section{References}

1. Lemos MC, Thakker RV. Multiple endocrine neoplasia type 1 (MEN1): analysis of 1336 mutations reported in the first decade following identification of the gene. Hum Mutat. 2008;29(1):22-32.

2. Skogseid B, Eriksson B, Lundqvist G, et al. Multiple endocrine neoplasia type 1: a 10-year prospective screening study in four kindreds. J Clin Endocrinol Metab. 1991;73(2):281287.

3. Ito $\mathrm{T}$, Igarashi $\mathrm{H}$, Uehara $\mathrm{H}$, et al. Causes of death and prognostic factors in multiple endocrine neoplasia type 1: a prospective study: comparison of $106 \mathrm{MEN1/Zollinger-Ellison}$ syndrome patients with 1613 literature MEN1 patients with or without pancreatic endocrine tumors. Medicine (Baltimore). 2013;92(3):135-181.

4. Burgess JR, Shepherd JJ, Parameswaran V, et al. Spectrum of pituitary disease in multiple endocrine neoplasia type 1 (MEN 1): clinical, biochemical, and radiological features of pituitary disease in a large MEN 1 kindred. J Clin Endocrinol Metab. 1996;81(7):2642-2646.

5. Vergès B, Boureille F, Goudet $P$, et al. Pituitary disease in MEN type 1 (MEN1): data from the France-Belgium MEN1 multicenter study. J Clin Endocrinol Metab. 2002;87(2):457465.

6. Burgess JR, Shepherd JJ, Parameswaran V, et al. Prolactinomas in a large kindred with multiple endocrine neoplasia type 1: clinical features and inheritance pattern. J Clin Endocrinol Metab. 1996;81(5):1841-1845.

7. Capella C, Riva C, Leutner M, La Rosa S. Pituitary lesions in multiple endocrine neoplasia syndrome (MENS) type 1. Pathol Res Pract. 1995;191(4):345-347.

8. de Laat JM, Dekkers OM, Pieterman CRC, et al. Long-term natural course of pituitary tumors in patients with MEN1: results from the DutchMEN1 Study Group (DMSG). J Clin Endocrinol Metab. 2015;100(9):3288-3296.

9. Farid NR, Buehler S, Russell NA, et al. Prolactinomas in familial multiple endocrine neoplasia syndrome type I. Relationship to HLA and carcinoid tumors. Am J Med. 1980;69(6):874-880.

10. O'Brien T, O'Riordan DS, Gharib H, et al. Results of treatment of pituitary disease in multiple endocrine neoplasia, type I. Neurosurgery. 1996;39(2):273-279.

11. Olufemi SE, Green JS, Manickam P, et al. Common ancestral mutation in the MEN1 gene is likely responsible for the prolactinoma variant of MEN1 (MEN1Burin) in four kindreds from Newfoundland. Hum Mutat. 1998;11(4):264-269.

12. Wu Y, Gao L, Guo X, et al. Pituitary adenomas in patients with multiple endocrine neoplasia type 1: a single-center experience in China. Pituitary. 2019;22(2):113-123.

13. Fernandez A, Karavitaki N, Wass JAH. Prevalence of pitu- 
itary adenomas: a community-based, cross-sectional study in Banbury (Oxfordshire, UK). Clin Endocrinol (Oxf). 2010;72(3):377-382.

14. Amar AP, Couldwell WT, Chen JCT, Weiss MH. Predictive value of serum prolactin levels measured immediately after transsphenoidal surgery. J Neurosurg. 2002;97(2):307-314.

15. Shrivastava RK, Arginteanu MS, King WA, Post KD. Giant prolactinomas: clinical management and long-term follow up. J Neurosurg. 2002;97(2):299-306.

16. Thakker RV, Newey PJ, Walls GV, et al. Clinical practice guidelines for multiple endocrine neoplasia type 1 (MEN1). J Clin Endocrinol Metab. 2012;97(9):2990-3011.

17. Giustina A, Chanson P, Bronstein MD, et al. A consensus on criteria for cure of acromegaly. J Clin Endocrinol Metab. 2010;95(7):3141-3148.

18. Nieman LK, Biller BMK, Findling JW, et al. Treatment of Cushing's syndrome: an Endocrine Society clinical practice guideline. J Clin Endocrinol Metab. 2015;100(8):2807-2831.

19. Marx S, Spiegel AM, Skarulis MC, et al. Multiple endocrine neoplasia type 1: clinical and genetic topics. Ann Intern Med. 1998;129(6):484-494.

20. Giusti F, Cianferotti L, Boaretto F, et al. Multiple endocrine neoplasia syndrome type 1: institution, management, and data analysis of a nationwide multicenter patient database. Endocrine. 2017;58(2):349-359.

21. Trump D, Farren B, Wooding C, et al. Clinical studies of multiple endocrine neoplasia type 1 (MEN1). QJM. 1996;89(9):653-669.

22. Oberg K, Skogseid B, Eriksson B. Multiple endocrine neoplasia type 1 (MEN-1). Clinical, biochemical and genetical investigations. Acta Oncol. 1989;28(3):383-387.

23. Faglia G. Epidemiology and pathogenesis of pituitary adenomas. Acta Endocrinol (Copenh). 1993;129(suppl 1):1-5.
24. Esposito D, Olsson DS, Ragnarsson O, et al. Non-functioning pituitary adenomas: indications for pituitary surgery and post-surgical management. Pituitary. 2019;22(4):422-434.

25. Karavitaki N, Collison K, Halliday J, et al. What is the natural history of nonoperated nonfunctioning pituitary adenomas? Clin Endocrinol (Oxf). 2007;67(6):938-943.

26. Sam AH, Shah S, Saleh K, et al. Clinical outcomes in patients with nonfunctioning pituitary adenomas managed conservatively. Clin Endocrinol (Oxf). 2015;83(6):861-865.

\section{Disclosures}

Dr. Bancos: consultant for Corcept and HRA Pharma.

\section{Author Contributions}

Conception and design: Cohen-Cohen, Brown. Acquisition of data: Cohen-Cohen, Wheeler, Singh Ospina. Analysis and interpretation of data: Cohen-Cohen, Brown, Himes, Singh Ospina. Drafting the article: Cohen-Cohen. Critically revising the article: Himes, Ruff, Atkinson, Meyer, Bancos, Young. Reviewed submitted version of manuscript: Van Gompel, Brown, Ruff, Atkinson, Meyer, Bancos, Young. Approved the final version of the manuscript on behalf of all authors: Van Gompel. Statistical analysis: Van Gompel, Brown, Himes, Wheeler, Major. Administrative/ technical/material support: Cohen-Cohen. Study supervision: Van Gompel.

\section{Correspondence}

Jamie J. Van Gompel: Mayo Clinic, Rochester, MN. vangompel.jamie@mayo.edu. 